\title{
Glycemic Control and Alveolar Bone Loss Progression in Type 2 Diabetes
}

\author{
George W. Taylor,* Brian A. Burt, $\uparrow$ Mark P. Becker, $\dagger$ Robert J. Genco, $\ddagger$ Marc Shlossman§ \\ *School of Dentistry, University of Michigan, Ann Arbor, MI. \\ + School of Public Health. \\ $\$$ School of Dental Medicine, Department of Oral Biology, State University of New York at Buffalo. \\ $\S$ Currently, private practice, Chandler, AZ; previously, State University of New York at Buffalo.
}

\begin{abstract}
This study tested the hypothesis that the risk for alveolar bone loss is greater, and bone loss progression more severe, for subjects with poorly controlled (PC) type 2 diabetes mellitus (type $2 \mathrm{DM}$ ) compared to those without type $2 D M$ or with better controlled (BC) type $2 \mathrm{DM}$. The PC group had glycosylated hemoglobin $\left(H b A_{1}\right) \geq 9 \%$; the $B C$ group had $\mathrm{HbA}_{1}<9 \%$. Data from the longitudinal study of the oral health of residents of the Gila River Indian Community were analyzed. Of the 359 subjects, aged 15 to 57 with less than $25 \%$ radiographic bone loss at baseline, 338 did not have type $2 \mathrm{DM}, 14$ were $B C$, and 7 were PC. Panoramic radiographs were used to assess interproximal bone level. Bone scores (scale 0-4) corresponding to bone loss of $0 \%, 1 \%$ to $24 \%, 25 \%$ to $49 \%, 50 \%$ to $74 \%$, or $\geq 75 \%$ were used to identify the worst bone score (WBS) in the dentition. Change in worst bone score at follow-up, the outcome, was specified on a 4-category ordinal scale as no change, or a 1-, 2-, 3-, or 4-category increase over baseline WBS (WBS1). Poorly controlled diabetes, age, calculus, time to follow-up examination, and WBS1 were statistically significant explanatory variables in ordinal logistic regression models. Poorly controlled type 2 DM was positively associated with greater risk for a change in bone score (compared to subjects without type 2 DM) when the covariates were included in the model. The cumulative odds ratio (COR) at each threshold of the ordered response was 11.4 (95\% CI $=2.5,53.3)$. When contrasted with
\end{abstract}

subjects with $B C$ type $2 D M$, the COR for those in the PC group was 5.3 (95\% CI $=0.8$, 53.3). The COR for subjects with $B C$ type 2 $D M$ was 2.2 (95\% CI =0.7, 6.5), when contrasted to those without type $2 \mathrm{DM}$. These results suggest that poorer glycemic control leads to both an increased risk for alveolar bone loss and more severe progression over those without type $2 \mathrm{DM}$, and that there may be a gradient, with the risk for bone loss progression for those with better controlled type 2 DM intermediate to the other 2 groups. Ann Periodontol 1998;3:30-39.

Key Words: Alveolar bone loss; diabetes mellitus, non-insulin-dependent; hyperglycemia; Indians, North American; periodontal diseases/epidemiology. 


\section{INTRODUCTION}

Diabetes mellitus is a heterogeneous group of disorders with different causes but all characterized by hyperglycemia, absolute or relative insulin deficiency or resistance to the action of insulin, and the tendency to develop certain long-term complications. The commonly recognized complications include accelerated atherosclerosis (macrovascular disease), diabetic retinopathy, diabetic nephropathy, and diabetic neuropathy. ${ }^{1}$

There are 4 major types of diabetes, with type 2 diabetes mellitus (formerly designated non-insulin-dependent diabetes mellitus) most prevalent. Approximately $90 \%$ to $95 \%$ of the estimated 7.8 million people in the United States diagnosed with diabetes have type 2 diabetes (type $2 \mathrm{DM}$ ), ${ }^{2}$ and virtually all people with diabetes aged $>45$ years have type $2 \mathrm{DM}^{3}{ }^{3}$ It is also estimated that for every diagnosed case of type $2 \mathrm{DM}$, there is approximately 1 undiagnosed case. ${ }^{3}$ The next most common type is type 1 diabetes mellitus (type $1 \mathrm{DM}$, formerly designated as insulin-dependent diabetes mellitus), occurring in $5 \%$ to $10 \%$ of diagnosed cases of diabetes. Diabetes associated with certain systemic conditions or syndromes comprises approximately $2 \%$ of all diagnosed cases of diabetes. These conditions include pancreatic disease, disease of hormonal etiology, drug- or chemical-induced conditions, abnormalities of insulin or its receptors, certain genetic syndromes, and other miscellaneous conditions. ${ }^{4}$ Approximately $2 \%$ to $5 \%$ of all pregnancies have associated gestational diabetes mellitus. ${ }^{5}$

The complications of diabetes, found in both type $2 \mathrm{DM}$ and type $1 \mathrm{DM}$, result from structural and functional changes in susceptible tissues. These complications rarely occur in individuals without the metabolic abnormalities, hyperglycemia and insulin deficiency (relative or absolute), that characterize diabetes mellitus. There has been extensive research to characterize the mechanisms responsible for the pathogenesis of both the microvascular and macrovascular complications, and several mechanisms have been hypothesized. These mechanisms include altered myoinositol metabolism, ${ }^{6}$ non-enzymatic glycosylation, ${ }^{7}$ altered hemodynamics, $^{8}$ and genetic factors. ${ }^{9-12}$ However, it is uncertain which of the hypothesized mechanisms, or combinations of mechanisms, is directly responsible in the target tissues for the pathogenesis of complications. It is also undetermined whether different mechanisms are operative in different tissues. It is known that not all people with diabetes experience these complications and that there is variability in the rate of development and severity of complications.

Strong evidence exists to support the notion that people with diabetes have increased risk for periodontitis. Indeed, periodontal disease has been recognized as another complication of diabetes. ${ }^{13}$ Many studies have reported an association between poor glycemic control and increased occurrence of periodontitis, ${ }^{14-29}$ although a number have also reported no association. ${ }^{30-42}$ Most of these studies involve type $1 \mathrm{DM}$ or do not specify the diabetes type; most are cross-sectional, thus unable to provide an estimate of glycemic control-related risk for poorer periodontal health; few use multivariate analysis; and none using sites or teeth as units of analysis accounts for extravariation (correlated observation) in the statistical analyses. The extensive variations in the design, conduct, and analyses of this set of studies contribute to inconsistencies in the findings. Consequently, no firm conclusions can be drawn from this collective body of literature. There are no previous reports that model risk for alveolar bone loss progression related to level of glycemic control of type $2 \mathrm{DM}$.

The purpose of this study was to test the hypothesis that the risk for alveolar bone loss is greater, and bone loss progression more severe, for subjects with poorly controlled type $2 \mathrm{DM}$ compared to those without type $2 \mathrm{DM}$ or with better controlled type 2 DM.

\section{MATERIALS AND METHODS}

Subjects for these analyses were 359 individuals, aged 15 to 57 , who were part of a longitudinal study of type 2. DM and perio- 
dontal disease in the Gila River Indian Community. Full details of this study have been presented elsewhere. ${ }^{43-45}$ There were 338 subjects free of diabetes at baseline who did not develop type $2 \mathrm{DM}$ during the follow-up period. The other 21 had type $2 \mathrm{DM}$ (14 with better controlled DM and 7 with poorly controlled DM) at baseline. Type 2 DM was defined as having a plasma glucose concentration $\geq 200 \mathrm{mg} / \mathrm{dL} 2$ hours after a $75 \mathrm{~g}$ oral glucose load following an overnight fast. Poorly controlled was defined as glycosylated hemoglobin $\left(\mathrm{HbA}_{1}\right)$ values $\geq 9 \%$ and better controlled as $\mathrm{HbA}_{1}<9 \%$. Subjects selected were those who had 20 or more teeth, lost no teeth during the follow-up period, and had less than $25 \%$ radiographic bone loss at baseline. The median time to follow-up was 2.3 years; the minimum and maximum follow-up periods were 1.2 and 6.9 years, respectively.

The response variable for these analyses was change in radiographic bone score, as determined from panoramic radiographs. The baseline worst bone score (WBS1) for the mesial and distal of each tooth was assessed on a 0 to 4 ordinal scale, using a modified Schei ruler ${ }^{45}$ with the score corresponding to percentage of root length not supported by interproximal bone. One value for each tooth, the greater of the mesial and distal measurements, was recorded. Bone scores corresponded to bone loss of $0 \%, 1 \%$ to $24 \%, 25 \%$ to $49 \%, 50 \%$ to $74 \%$, or $\geq 75 \%$. Change in bone score category (WBSch), the outcome of interest in this analysis, was computed as the greatest difference between baseline worst bone score (WBS1) and worst bone score at follow-up (WBS2). This outcome was specified as a 4-category ordinal scale representing no change, a 1-category increase, 2-category increase, or 3- or 4-category increase over WBS1.

Glycemic control status, the principal exposure in these analyses, was specified as 2 indicator variables, better control $\left(\mathrm{HbA}_{1}<\right.$ 9\%) and poorer control $\left(\mathrm{HbA}_{1} \geq 9 \%\right)$. Additional dental, behavioral, medical, and demographic variables were evaluated at their baseline values for confounding and effect modification. Age, calculus index; ${ }^{46}$ plaque index, ${ }^{47}$ gingival index, ${ }^{48}$ and time to follow- up examination were used in the models as continuous covariates. Indicator variables were defined for WBS1 $(0 \%$ or $1 \%$ to $24 \%$ ), self-reported alcohol consumption $\geq 3$ drinks/day), smoking (any smoking in the year preceding baseline), obesity (body mass index $>27 \mathrm{~kg} / \mathrm{m}^{2}$ ), coronary artery disease, and gender.

Statistical analyses consisted of contingency table analysis and regression modeling. Contingency tables were used to assess relationships among variables for sparseness and patterns of possible confounding or effect modification. Regression modeling consisted of developing ordinal logistic regression models with cumulative logits, ${ }^{49}$ using an ordinal specification for WBSch, to test the effects of other covariates on the WBSch-glycemic control association. Use of cumulative logits to analyze the ordinal response provided a way to analyze both the incidence of any change of periodontal status over time, as well as the severity of change, where change in periodontal status in subjects was ordinally defined at follow-up as no change, or a 1-, 2-, 3-, or 4category increase. Parameter estimates obtained from this approach also allowed estimating the probability of making any change, as well as a 1-category leap, 2-category leap, and so on, over the follow-up period.

The regression models were developed in stages. First, using a forward stepwise selection procedure," all the dental, behavioral, medical, and demographic variables considered to be important risk factors or confounders were included in a model, with the 2 indicator variables for glycemic control forced to remain in each model tested (the reference category included all subjects without type 2 DM). This initial selection step resulted in a preliminary candidate model. Next, each of the variables that had been previously eliminated in the stepwise selection procedure was separately retested in this candidate model and retained if it attained a level of significance with $P$ value $<0.05$. Following testing for main effects, first-order interaction terms were tested in the candidate model for relations between baseline age or glycemic

|Proc Logistic, SAS Institute Inc., Cary, NC. 
Table 1. Baseline descriptors*

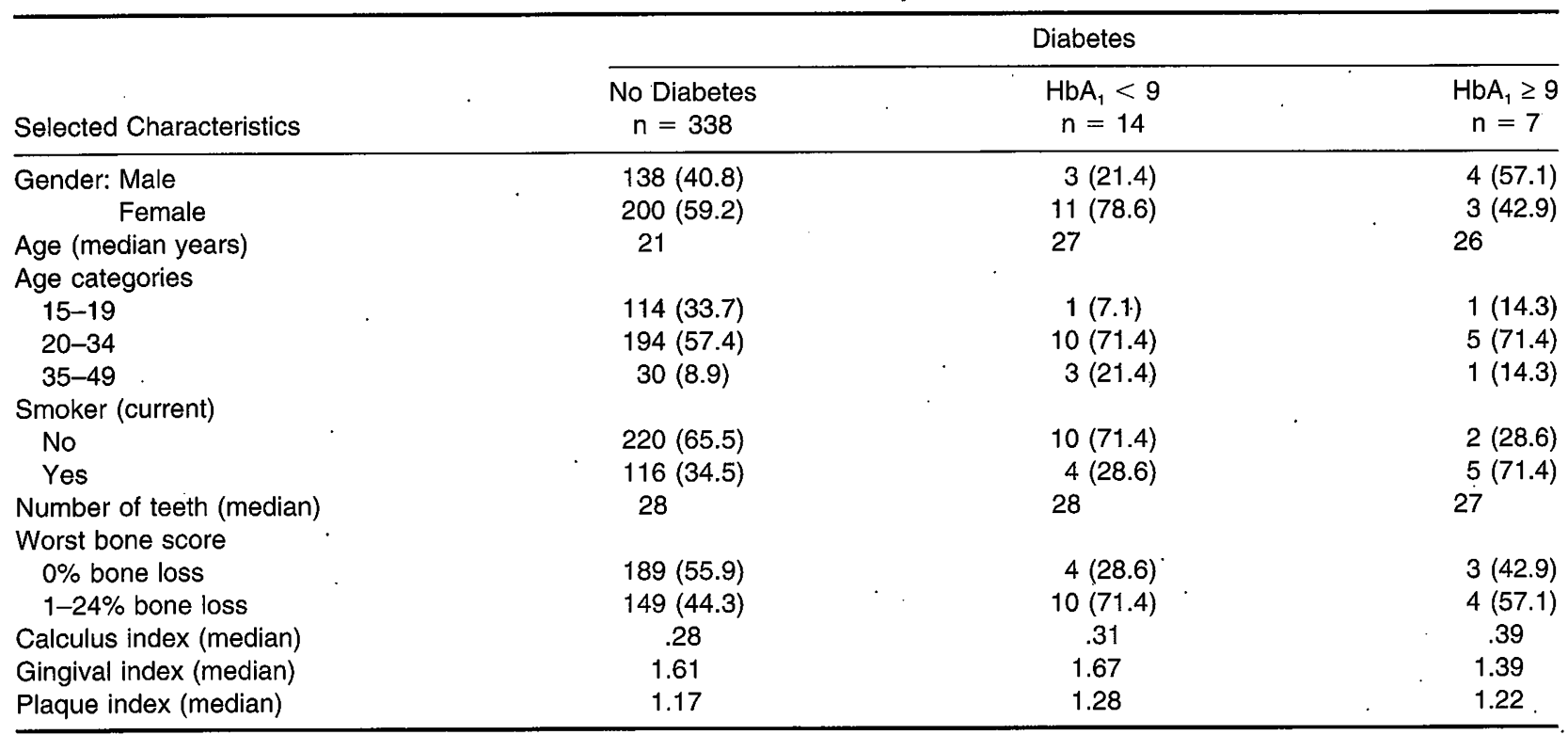

*Percentage of subjects shown in parentheses.

control and all the main effects variables and for relations between baseline periodontal status and selected covariates. Quadratic terms were tested for all continuous covariates. Using likelihood ratio tests for the ordinal logistic regression models, terms found not to be statistically significant at the 0.05 level or important as effect modifiers or confounders in the modeled relationships were eliminated. Parameter estimate interpretation incorporated the point estimate as well as the 95\% confidence interval in testing the ability to reject the null hypothesis. After obtaining a parsimonious model, the model fit was evaluated by using the likelihood ratio chi-squared test statistic, score test for the proportional odds assumption, and residual analysis.

\section{RESULTS}

Table 1 presents selected descriptive baseline statistics of the subjects without type 2 DM contrasted with 21 subjects with type 2 DM classified by level of glycemic control (i.e., better controlled and poorly controlled). Among subjects with better control, a notably higher proportion was female, while among those with poorer control, a somewhat higher proportion was male. The median ages for subjects with better control and for those with poorer control were similar, although both groups were slightly older than the group without type 2 DM. The proportion of current smokers was slightly higher in the group without type $2 \mathrm{DM}$ compared to the group with type $2 \mathrm{DM}$ who were better controlled, but there was a notably higher proportion of current smokers in the group with poorly controlled type $2 \mathrm{DM}$ compared to both of the other 2 groups. (Data on smoking status were missing for 2 subjects in the "No Diabetes" group.) The median number of teeth was equivalent for the 3 groups, and the calculus and plaque indices were similar. The gingival index was similar for those without type $2 \mathrm{DM}$ and better controlled groups but slightly lower in the poorly controlled group.

Table 2 shows the bivariate relationships between degree of WBSch, glycemic control status, and other selected baseline characteristics. There was a notable trend for the proportion of subjects experiencing no WBSch to diminish as glycemic control status worsened, with $59.5 \%$ of those without type $2 \mathrm{DM}, 42.9 \%$ of the better controlled, and only $1(14.3 \%)$ of the poorly controlled subjects having no WBSch at follow-up. Although the number of subjects with type 2 DM was small in the last 2 categories of 
Table 2. Change in worst bone score by selected baseline characteristics (percentage of subjects in each row of each variable is shown in parentheses for the categories of change in worst bone score)

\begin{tabular}{|c|c|c|c|c|c|}
\hline \multirow{2}{*}{$\begin{array}{l}\text { Baseline } \\
\text { Characteristics }\end{array}$} & \multicolumn{5}{|c|}{ Degree of Change in Worst Bone Score at Follow-Up } \\
\hline & None & 1 & 2 & $3-4$ & $N$ \\
\hline \multicolumn{6}{|l|}{ Diabetes } \\
\hline No diabetes & $201(59.5)$ & $126(37.3)$ & $7(2.1)$ & $4(1.2)$ & 338 \\
\hline $\mathrm{HbA}_{1}<9 \%$ & $6(42.9)$ & $6(42.9)$ & $2(14.3)$ & 0 & 14 \\
\hline $\mathrm{HbA}_{1} \geq 9 \%$ & $1(14.3)$ & $4(57.1)$ & $1(14.3)$ & $1(14.3)$ & 7 \\
\hline \multicolumn{6}{|l|}{ Gender } \\
\hline Male & $75(51.7)$ & $64(44.1)$ & $3(2.1)$ & $3(2.1)$ & 145 \\
\hline Female & $133(62.1)$ & $72(33.6)$ & $7(3.3)$ & $2(0.9)$ & 214 \\
\hline \multicolumn{6}{|l|}{ Age } \\
\hline $15-19$ & $83(71.5)$ & $31(26.7)$ & $2(1.7)$ & 0 & 116 \\
\hline $20-34$ & $114(54.5)$ & $87(41.6)$ & $5(2.4)$ & $3(1.4)$ & 209 \\
\hline $35-57$ & $11(32.3)$ & $18(52.9)$ & $3(8.8)$ & $2(5.9)$ & 34 \\
\hline \multicolumn{6}{|l|}{ Smoker } \\
\hline No & $134(57.8)$ & $89(38.4)$ & $7(3.0)$ & $2(0.9)$ & 232 \\
\hline Yes & $72(57.6)$ & $47(37.6)$ & $3(2.4)$ & $3(2.4)$ & 125 \\
\hline \multicolumn{6}{|l|}{ Worst bone score } \\
\hline $0 \%$ & $101(51.5)$ & $84(42.9)$ & $8(4.1)$ & $3(1.5)$ & 196 \\
\hline $1-24 \%$ & $107(65.6)$ & $52(31.9)$ & $2(1.2)$ & $2(1.2)$ & 163 \\
\hline \multicolumn{6}{|l|}{ Calculus index } \\
\hline Lower 50thpctile & $117(62.6)$ & $63(33.7)$ & $4(2.1)$ & $3(1.6)$ & 187 \\
\hline Upper 50thpctile & $91(52.9)$ & $73(42.4)$ & $6(3.5)$ & $2(1.2)$ & 172 \\
\hline
\end{tabular}

Table 3. Cumulative logistic regression model* (No Diabetes is the referent group)

\begin{tabular}{|c|c|c|c|c|}
\hline Covariate & Beta & Standard Error & $P$ Value & Odds Ratio $(95 \% \mathrm{Cl})$ \\
\hline \multicolumn{5}{|l|}{ Main Effects } \\
\hline Intercept 1 & -3.385 & .513 & .0001 & NA \\
\hline Intercept 2 & -6.699 & .647 & .0001 & NA \\
\hline Intercept 3 & -7.886 & .753 & .0001 & NA \\
\hline $\mathrm{HbA}_{1}<9 \%$ & 0.769 & .567 & .1750 & $2.2(0.7,6.5)$ \\
\hline $\mathrm{HbA}_{1} \geq 9 \%$ & 2.438 & .785 & .0019 & $11.4(2.5,53.3)$ \\
\hline No diabetes & NA & NA & NA & 1.0 (ref. group) \\
\hline Age & 0.104 & .018 & .0001 & $1.1(1.1,1.2)$ \\
\hline Time to follow-up & 0.306 & .106 & .0038 & $1.4(1.1,1.7)$ \\
\hline WBS1 & -1.749 & .292 & .0001 & $0.2(0.1,0.3)$ \\
\hline Calculus index & 1.087 & .281 & .0001 & $3.0(1.7,5.1)$ \\
\hline
\end{tabular}

*Model evaluation statistics: likelihood ratio chi-squared statistic $=79.4$ ( 6 degrees of freedom), $P=.0001$; score test for the proportional odds assumption $=14.3(12$ degrees of freedom), $P=.2841$.

WBSch, there was a tendency for the subjects with poorer control to have a higher proportion with more severe bone loss (i.e., a 1-, 2-, 3-, or 4-category change). The 3 age groups in Table 2 reflected a pattern of increasing severity of WBSch as age increased. The pattern of bone loss for smokers and nonsmokers was equivalent, except possibly the most severe category. Subjects with some evidence of radiographic bone loss at baseline (WBS1 of $1 \%$ to $24 \%$ ), also shown in Table 2, tended to have less severe WBSch at follow-up (i.e., higher proportion with no change at follow-up and lower proportions in each of the other WBSch categories). Finally, subjects with a calculus index score greater than the median generally exhibited greater progression of bone loss.

Table 3 shows the results of the final ordinal logistic regression model used to test the hypothesis that the risk for alveolar bone loss is greater, and bone loss progression more severe, for subjects with poorly controlled type $2 \mathrm{DM}$ than for those without type 2 DM (the referent group in this model). The coefficient estimates, $P$ values, odds ratios 
(with 95\% confidence limits), and model evaluation statistics are shown. This model suggests that subjects with better controlled type 2 DM may not have a statistically significantly greater risk for alveolar bone loss progression than subjects without type $2 \mathrm{DM}$, as evidenced by the $P$ value of 0.1750 for the coefficient for better control term $\left(\mathrm{HbA}_{1}<9\right)$; the odds ratio of 2.2 includes 1 in its $95 \%$ confidence interval $(0.7,6.5)$. The model estimates that subjects with poorly controlled type $2 \mathrm{DM}\left(\mathrm{HbA}_{1} \geq 9 \%\right)$ have a significantly higher risk for alveolar bone loss, as well as more severe bone loss progression at followup, than subjects without type $2 \mathrm{DM}$; the odds ratio is $11.4(95 \% \mathrm{CI}=2.5,53.3)$. This final model also estimated significant effects for time to follow-up and baseline values for age, calculus, and WBS. There was no significant risk associated with alcohol consumption, smoking, obesity, systolic blood pressure, coronary artery disease, gender, or number of teeth in the final model.

Table 4 shows the results of the final ordinal logistic regression model used to test the hypothesis that the risk for alveolar bone loss over 2 years is greater, and bone loss progression more severe, for subjects with poorly controlled type $2 \mathrm{DM}$ than for those with better controlled type $2 \mathrm{DM}$. To test this hypothesis, the model is specified with indicator variables for subjects with poorly controlled type $2 \mathrm{DM}\left(\mathrm{HbA}_{1} \geq 9 \%\right)$ and for those without type $2 \mathrm{DM}$. In this table, the referent group consists of those subjects with better controlled type $2 \mathrm{DM}\left(\mathrm{HbA}_{1}<9 \%\right)$. This model shows that subjects with poorly controlled type 2 DM may not have a statistically significantly greater risk for alveolar bone loss progression than subjects with better control, as evidenced by the $P$ value of 0.0751 for the coefficient for the poorer control term $\left(\mathrm{HbA}_{1} \geq 9 \%\right)$; the odds ratio of 5.3 includes 1 in its $95 \%$ confidence interval $(0.8,33.4)$. This interpretation is made with caution because the size of the odds ratio and wide confidence interval having the lower bound at 0.8 suggest that there may indeed be a difference between those with poorer control and those with better control, although not as strong as the contrast between those with poorer control and those without type $2 \mathrm{DM}$.
As expected, the remainder of the parameters estimated by this model mirrors those shown in Table 3.

Figure 1 contrasts the probabilities of change in bone score category estimated by the ordinal logistic regression model (using the parameter estimates of Table 3). It shows that the probability of a 1-, 2-, 3-, or 4-category change in radiographic worst bone score was greatest for subjects with poorly controlled type 2 DM (e.g., subjects with poorly controlled type $2 \mathrm{DM}$ had a probability of 0.29 for a 2 -category change, while the probability for those with better control was 0.16 , and for those without diabetes 0.09). The figure also shows a gradient in the effect of type $2 \mathrm{DM}$ on the probability of bone loss progression, with risk increasing as glycemic control worsens.

\section{DISCUSSION}

The results from these analyses provide strong evidence to support the hypothesis that the risk for alveolar bone loss over 2 years is greater, and bone loss progression more severe, for subjects with poorly controlled type 2 DM than those without type 2 DM. The results provide somewhat more equivocal evidence in testing the hypothesis that the risk for alveolar bone loss and its severity is greater for those with poorer control than those with better control. The effect parameter for those with poorly controlled type $2 \mathrm{DM}\left(\mathrm{HbA}_{1} \geq 9 \%\right)$, estimated in the model with better control $\left(\mathrm{HbA}_{1}<9 \%\right)$ as the referent group in Table 4 , is not statistically significant when a $P$ value $<0.05$ is used as the cut-off. However, the size of the effect (odds ratio $=5.3$ ), width of the confidence interval $(.8,33.4)$, and nearness of the lower boundary of the $95 \%$ confidence interval to 1 , as shown in Table 4, suggest that those with poorer control may have greater risk than those with better control. The absence of statistical significance in this case may be due to the small numbers of subjects with better control and poorer control, leading to reduced power to detect significant differences in these analyses. The same may hold for the absence of statistical significance in contrasting the risk for those with better control with 
Table 4. Cumulative logistic regression model ${ }^{\star}\left(\mathrm{HbA}_{1}<9 \%\right.$ is the referent group)

\begin{tabular}{lcccc}
\hline Covariate & Beta & Standard Error & $P$ Value & Odds Ratio (95\% Cl) \\
\hline Main Effects & & & & NA \\
Intercept 1 & -7.118 & .936 & .0001 & NA \\
Intercept 2 & -5.931 & .856 & .0001 & NA \\
Intercept 3 & -2.616 & .777 & .0008 & NA \\
$\mathrm{HbA}_{1}<9 \%$ & $\mathrm{NA}$ & $\mathrm{NA}$ & .0751 & 1.0 (ref. group) \\
$\mathrm{HbA}_{1} \geq 9 \%$ & 1.669 & .938 & .1750 & $5.3(0.8,33.4)$ \\
No diabetes & -0.769 & .567 & .0001 & $0.5(0.1,1.4)$ \\
Age & 0.104 & .018 & .0038 & $1.1(1.1,1.2)$ \\
Time to follow-up & 0.306 & .106 & .0001 & $1.4(1.1,1.7)$ \\
WBS1 & -1.749 & .292 & .0001 & $0.2(0.1,0.3)$ \\
Calculus index & 1.087 & .281 & $3.0(1.7,5.1)$ \\
\hline
\end{tabular}

*Model evaluation statistics: likelihood ratio chi-squared $=.79 .4$ (6 DF), $P=.0001$; score test for the proportional odds assumption $=14.3$ (12 DF), $P=.2841$.

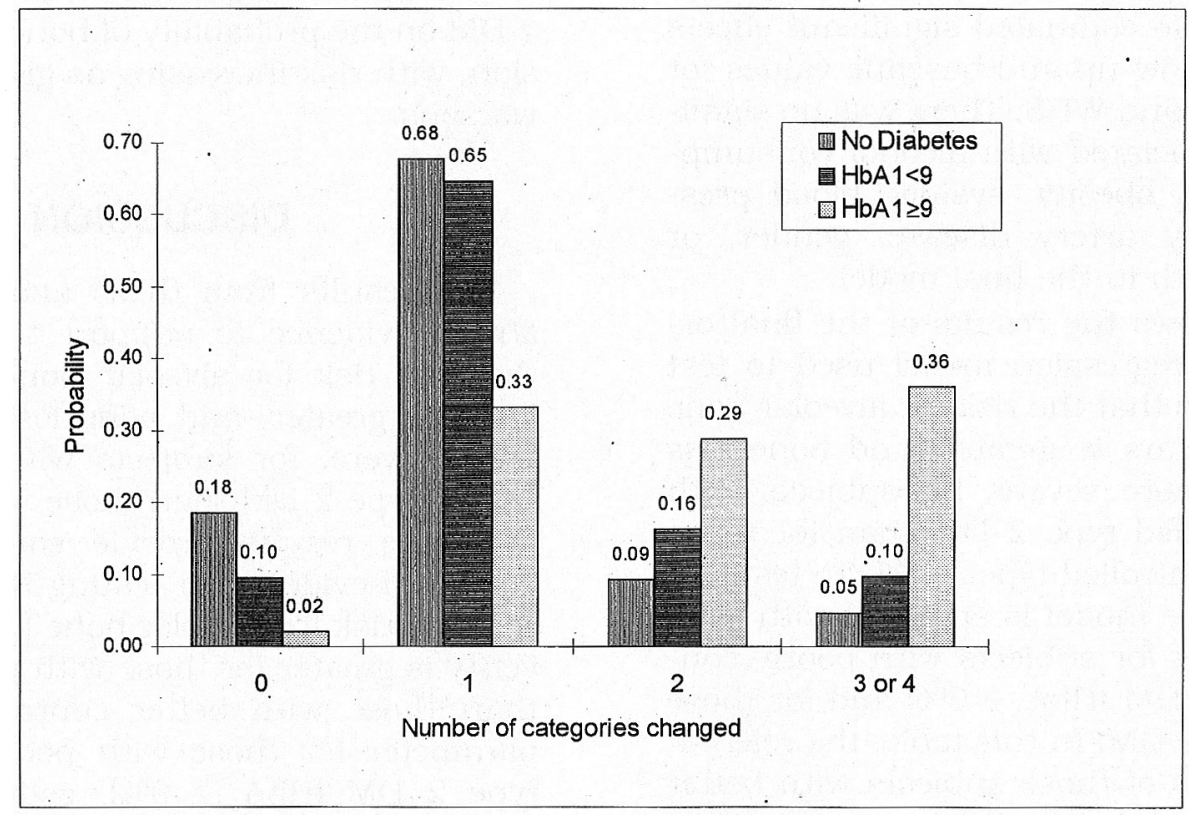

Figure 1. Probabilities of change in worst bone score category.

those who do not have type 2 DM. Given the small sample sizes in the poorly controlled and better controlled groups, the size and statistical significance of the effect estimated for the poorly controlled group, and the presence in the models of other covariates known to be associated with progression of periodontal diseases, the evidence is strengthened for the contrast in risk for those with poorly controlled type 2 DM over those without type 2 DM. Further, the results from these analyses suggest that there may be a gradient in risk for alveolar bone loss and severity of its progression, as illustrated in Figure 1, with the risk for poorer control $>$ risk for better control $>$ risk for those without type 2 DM.

In general, the direction of the effects for the other covariates in the logistic regression models is as expected, except for WBS 1 . The models suggest that there may be an inverse relationship between WBS1 and WBSch at follow-up; i.e., there was a higher risk of WBSch in subjects with no measurable radiographic bone loss (maximum WBS $=0 \%$ ) than in subjects with maximum WBS of $1 \%$ to $24 \%$ at baseline. Papapanou and Wennstrom $^{50}$ also found an inverse relationship between baseline radiographic bone level and 
amount of bone loss at follow-up. However, Albandar ${ }^{51}$ reported a direct relationship between degree of bone loss at baseline and at follow-up. Consideration of the unit of analysis may provide resolution of these seemingly divergent findings. As was the case with Papapanou and Wennstrom, ${ }^{50}$ the individual in the present study is the analytic unit rather than the tooth or site, as was the case in Albandar. ${ }^{51}$

The stringent subject selection criteria employed in these analyses resulted in a considerable reduction in the number of subjects with type $2 \mathrm{DM}$ and potentially weakened statistical power to detect significant differences between the groups. The motivation for choosing subjects who had 20 or more teeth at baseline, lost no teeth during the follow-up period, had WBS $1 \leq 24 \%$, and whose diabetes status did not change during the follow-up period was to reduce the extraneous effects of other factors as much as possible. These strict selection criteria could have led to a selection bias. However, the selection bias in these analyses, if present, would be towards selecting the "healthiest" of the type $2 \mathrm{DM}$ subjects, and hence would bias results against rejecting the null hypothesis. Since the analyses resulted in a well-fitting model that permitted rejecting the null hypothesis for contrasting WBSch in the poorly controlled versus non-type $2 \mathrm{DM}$ groups, the potential selection bias actually provides more confidence in the conclusions reached.

Prior to accepting the results from the models presented, several tests were performed to assess the effects of the stringent selection criteria. Separate data sets with larger numbers were created to test the consistency of the effect of poorer control where WBS1 was $\leq 2(0 \%$ to $49 \%)$ instead of $\leq 1(0 \%$ to $24 \%$ ), where minimum number of teeth at baseline was 12 rather than 20 , and where subjects with tooth loss were not excluded. The results (not shown) of models incorporating these relaxed inclusion criteria were not superior to those presented here. The supplemental model that included subjects who lost teeth during the follow-up period (but otherwise met the inclusion criteria) had 401 observations and estimated an improvement in the statistical significance for the ef- fect of being in the better controlled group, with an odds ratio of $2.8(95 \% \mathrm{CI}=0.99,7.8$; $P$ value $=0.052$ ). This result further supports our suggestion of a gradient of risk related to glycemic control. However, this supplemental ordinal logistic regression model did not fit quite as well (score test $P$ value $=0.0678$ ) as the final model presented. This worsening of the model fit, combined with the relaxed inclusion criteria, lessened our confidence in using this model as our final model. Hence, the results of the more conservative analyses are presented in the tables.

The principal exposure in these analyses was glycemic control status, formed by dichotomizing the continuous values for glycosylated hemoglobin $\left(\mathrm{HbA}_{1}\right)$. The cut point of $9 \%$ or more, used to distinguish those with poorer control from those with better control, -was chosen because it is near the $\mathrm{HbA}_{1}$ antimode in this population. ${ }^{52} \mathrm{~A}$ potential limitation in these analyses is choosing a cut point for the $\mathrm{HbA}_{1}$ measures. By dichotomizing baseline $\mathrm{HbA}_{1}$, subjects with values slightly above or below the cut point would tend to be similar with respect to glycemic control status, although classified as having a different exposure in the analysis. This imposed dichotomous classification of better versus poorer control could weaken the power to detect an effect on alveolar bone loss severity by assigning subjects with similar baseline glycemic control characteristics to different exposure categories. To address this issue, we conducted a supplemental analysis by creating a "buffer zone" to identify and exclude subjects who had $\mathrm{HbA}_{1}$ values from $8 \%$ to $9 \%$. This supplemental analysis excluded 3 subjects, all in the group with better controlled type 2 DM. Even with the loss of 3 of the better controlled subjects, we observed minimal changes in the results of the logistic regression model that was otherwise identical to the model presented in Table 4 . Hence, it is not likely that misclassification of glycemic control status had a substantial role in these analyses.

These results support and extend other reports in the literature describing an association between poor glycemic control and periodontal disease. This study has evaluated the effects of glycemic control status on both 
the risk for, as well as severity of, periodontal destruction over time. The temporal sequence specified in these longitudinal analyses provides evidence to support a cause-effect relationship. Subjects with poorer glycemic control had significantly greater risk for alveolar bone loss progression, and the progression was more severe than in subjects without type 2 DM. Additionally, these analyses suggest that there may be a gradient in risk for any alveolar bone loss, as well as severity of progression of alveolar bone loss, with poorly controlled $>$ better controlled $>$ no type $2 \mathrm{DM}$.

\section{Acknowledgments}

This study was supported by the Michigan Diabetes Research and Training Center and by NIDR grants DE06514 and DE07157. We wish to acknowledge Dr. Lynn Budding for his consultation and field work in helping to collect the oral health data; Ms. Ana CabreraArevalo for assistance in data management and computer programming; and the members and leaders of the Gila River Indian Community for generously participating in and encouraging the study.

\section{REFERENCES}

1. Santiago JV. Overview of the complications of diabetes. Clin Chem 1986;32(suppl.):B48-B53.

2. Harris MI. Summary. In: National Diabetes Data Group. Diabetes in America, 2nd ed. Washington DC: Government Printing Office; 1995:I-1-13. NIH publication no. 95-1468.

3. Kenny SJ, Aubert RE, Geiss LS. Prevalence and incidence of non-insulin-dependent diabetes. In: $\mathrm{Na}$ tional Diabetes Data Group. Diabetes in America, 2nd ed. Washington DC: Government Printing Office; 1995:IV-47-68. NIH publication no. 95-1468.

4. World Health Organization. Diabetes Mellitus: Report of a WHO Study Group. Geneva, Switzerland: World Health Organization; 1985. Technical report series 727 .

5. Harris MI. Prevalence of non-insulin-dependent diabetes and impaired glucose tolerance. In: National Diabetes Data Group. Diabetes in America. Washington DC: Government Printing Office; 1985:II-110. NIH publication no. 85-1468.
6. Greene DA, Lattimer SA. Biochemical alterations and complications in diabetes. Clin Chem 1986; 32(suppl.):B42-B47.

7. Brownlee M, Vlassara H, Cerami A. Nonenzymatic glycosylation and the pathogenesis of diabetic complications. Ann Intern Med 1984; 101:527-537.

8. Brenner BM, Anderson S. Glomerular function in diabetes mellitus. Adv Nephrol 1990;19:135-144.

9. Bennett PH, Nelson RG, Pettitt DJ, Knowler WC. Risk factors for vascular complications of NIDDM. In: Alberti KGMM, Mazze RS, eds. Frontiers of Diabetes Research: Current Trends in Non-Insulin-Dependent Diabetes Mellitus. New York: Elsevier; 1989:89-99.

10. Pettitt DJ, Saad MF, Bennett PH, Nelson RG, Knowler WC. Familial predisposition to renal disease in 2 generations of Pima Indians with Type 2 (non-insulin-dependent) diabetes mellitus. Diabetologia 1990;33:438-443.

11. Committee on Diabetic Twins, Japan Diabetes Society. Diabetes mellitus in twins: A cooperative study in Japan. Diabetes Res Clin Practice 1988;5: 271-280.

12. Seaquist ER, Goetz FC, Rich S, Barbosa J. Familial clustering of diabetic kidney disease. Evidence for genetic susceptibility to diabetic nephropathy. $N$ Engl J Med 1989;320:1161-1 165.

13. Löe H. Periodontal disease: The sixth complication of diabetes mellitus. Diabetes Care 1993;16(suppl.): 329-334.

14. Seppala B, Ainamo J. A site-by-site follow-up study on the effect of controlled versus poorly controlled insulin-dependent diabetes mellitus. $J$ Clin Periodontol 1994;21:161-165.

15. Tervonen T, Oliver RC. Long-term control of diabetes mellitus and periodontitis. $J$ Clin Periodontol 1993;20:431-435.

16. Seppala B, Seppala M, Ainamo J. A longitudinal study on insulin-dependent diabetes mellitus and periodontal disease. $J$ Clin Periodontol 1993;20: 161-165.

17. Oliver RC, Tervonen T. Periodontitis and tooth loss: Comparing diabetics with the general population. $J$ Am Dent Assoc 1993;124:71-76.

18. Unal T, Firatli E, Sivas A, Meric $\mathrm{H}, \mathrm{Oz} \mathrm{H}$. Fructosamine as a possible monitoring parameter in noninsulin-dependent diabetes mellitus patients with periodontal disease. $J$ Periodontol 1993;64:191194.

19. Safkan-Seppala B, Ainamo J. Periodontal conditions in insulin-dependent diabetes mellitus. $J$ Clin Periodontol 1992;19:24-29.

20. Cutler CW, Eke P, Arnold RR, Van Dyke TE. Defective neutrophil function in an insulin-dependent diabetes mellitus patient. A case report. $J$ Periodontol 1991;62:394-401.

21. Ainamo J, Lahtinen A, Uitto VJ. Rapid periodontal destruction in adult humans with poorly controlled diabetes. A report of 2 cases. $J$ Clin Periodontol 1990;17:22-28.

22. Gusberti FA, Syed SA, Bacon G, Grossman N, Loesche WJ. Puberty gingivitis in insulin-dependent diabetic children. J Periodontol 1983;54:714-720. 
23. Harrison R, Bowen WH. Periodontal health, dental caries, and metabolic control in insulin-dependent diabetic children and adolescents. Pediatr Dent 1987;9:283-286.

24. Galea H, Aganovic I, Aganovic M. The dental caries and periodontal disease experience of patients with early-onset insulin-dependent diabetes. Int Dent $J$ $1986 ; 36: 219-224$.

25. Tervonen T, Knuuttila M. Relation of diabetes control to periodontal pocketing and alveolar bone level. Oral Surg Oral Med Oral Pathol 1986;61:346349.

26. Ervasti T, Knuuttila M, Pohjamo L, Haukipuro K. Relation between control of diabetes and gingival bleeding. J Periodontol 1985;56:154-157.

27. Gislen G, Nilsson KO, Matsson L. Gingival inflammation in diabetic children related to degree of metabolic control. Acta Odontol Scand 1980;38:241246.

28. Kjellman O, Henriksson CO, Berghagen N, Andersson $\mathrm{B}$. Oral conditions in 105 subjects with insulintreated diabetes mellitus. Swed Dent J 1970;63:99110.

29. Finestone AJ, Boorujy SR. Diabetes mellitus and periodontal disease. Diabetes 1967;16:336-340.

30. Bacic M, Plancak D, Granic M. CPITN assessment of periodontal disease in diabetic patients. $J$ Periodontol 1988;59:816-822.

31. Hove KA, Stallard RE. Diabetes and the periodontal patient. J Periodontol 1970;41:713-718.

32. Wolf J. Dental and periodontal conditions in diabetes mellitus. A clinical and radiographic study. Proc Finn Dent Soc 1977;73(suppl.): 1-56.

33. Albrecht M, Banoczy J, Tamas G. Dental and oral symptoms of diabetes mellitus. Commun Dent Oral Epidemiol 1988;16:378-380.

34. Barnett ML, Baker RL, Yancey JM, MacMillan DR, Kotoyan M. Absence of periodontitis in a population of insulin-dependent diabetes mellitus (IDDM) patients. J Periodontol 1984;55:402-405.

35. De Pommereau V, Dargent-Paré C, Robert JJ, Brion M. Periodontal status in insulin-dependent diabetic adolescents. J Clin Periodontol 1992;19:628-632.

36. Hayden P, Buckley LA. Diabetes mellitus and periodontal disease in an Irish population. $J$ Periodont Res 1989;24:298-302.

37. Nichols C, Laster LL, Bodak-Gyovai LZ. Diabetes mellitus and periodontal disease. $J$ Periodontol 1978;49:85-88.

38. Rylander H, Ramberg P, Blohme G, Lindhe J. Prevalence of periodontal disease in young diabetics. $J$ Clin Periodontol 1987;14:38-43.

39. Sandholm L, Swanljung O, Rytomaa I, Kaprio EA, Maenpaa J. Periodontal status of Finnish adolescents with insulin-dependent diabetes mellitus. $J$ Clin Periodontol 1989;16:617-620.
40. Sandholm L, Swanljung O, Rytomaa I, Kaprio EA, Maenpaa J. Morphotypes of the subgingival microflora in diabetic adolescents in Finland. $J$ Periodontol 1989;60:526-528.

41. Sastrowijoto SH, Hillemans P, van Steenbergen TJM, Abraham-Inpijn L, de Graaff J. Periodontal condition and microbiology of healthy and diseased periodontal pockets in type 1 diabetes mellitus patients. J Clin Periodontol 1989;16:316-322.

42. Thorstensson H, Kuylenstierna J, Hugoson A. Medical status and complications in relation to periodontal disease experience in insulin-dependent diabetics. J Clin Periodontol 1996;23:194-202.

43. Knowler WC, Bennett PH, Hamman RF, Miller M. Diabetes incidence and prevalence in Pima Indians: A 19-fold greater incidence than in Rochester, Minnesota. Am J Epidemiol 1978;108:497-505.

44. Shlossman M, Knowler WC, Pettitt DJ, Genco RJ. Type 2 diabetes mellitus and periodontal disease. $J$ Am Dent Assoc 1990;121:532-536.

45. Taylor GW, Burt BA, Becker MP, et al. Severe periodontitis and risk for poor glycemic control in subjects with non-insulin-dependent diabetes mellitus. $J$ Periodontol 1996;67(suppl.):1085-1093.

46. Ramfjord SP. Indices for prevalence and incidence of periodontal disease. J Periodontol 1959;30:5159.

47. Silness J, Löe H. Periodontal disease in pregnancy. II. Correlation between oral hygiene and periodontal condition. Acta Odontol Scand 1964;22:112-135.

48. Löe H, Silness J. Periodontal disease in pregnancy. I. Prevalence and severity. Acta Odontol Scand 1963;21:533-551.

49. Koch GC, Beck JD. Statistical methodologies useful for the analysis of data from risk-assessment studies. J Public Health Dent 1992;3:146-167.

50. Papapanou PN, Wennstrom JL. A 10-year retrospective study of periodontal disease progression. Clinical characteristics of subjects with pronounced and minimal disease development. $J$ Clin Periodontol 1990;17:78-84.

51. Albandar JM. Some predictors of radiographic alveolar bone height reduction over 6 years. $J$ Periodont Res 1990;25:186-192.

52. McCance DR, Hanson RL, Charles M-A, et al. Comparison of tests for glycated haemoglobin and fasting and two hour plasma glucose concentrations as diagnostic methods for diabetes. $\mathrm{Br}$ Med $J$ 1994; 308:1323-1328.

Send reprint requests to: Dr. George W. Taylor, Department of Cariology, Restorative Sciences, and Endodontics, University of Michigan School of Dentistry, 1011 N. University, Ann Arbor, MI 48109-1078. Fax: 313/936-1597; e-mail: gwt@umich.edu

Accepted for publication February 5, 1998. 